\title{
INTERFACE GRÁFICA DO USUÁRIO PARA APLICATIVO DE GESTÃO DE ESTOQUE DA CONTAAZUL PARA DISPOSITIVO DE INTERAÇÃO MÓVEL TIPO TABLETS
}

Roy Ristow Wippel Schulenburg

Universidade da Região de Joinville

roy@univille.br

Haro Ristow Wippel Schulenburg Universidade da Região de Joinville haro@univille.br
Iohana Cristina Pereira Pinto

Universidade da Região de Joinville

iohana.cristina@gmail.com

Gabriela Renata Rosa

Universidade da Região de Joinville gabrielarr_@hotmail.com

Resumo: Com o crescente aumento da venda de tablets, torna-se cada vez mais necessária a adaptação de serviços para tais dispositivos, a fim de garantir uma usabilidade eficiente em todas as plataformas - demanda ainda em aberto na startup de gestão financeira online ContaAzul. A partir disto, foi desenvolvido uma proposta de interface para aplicativo de gestão de estoques para a ContaAzul, orientada sobre os critérios de experiência do usuário. Para o desenvolvimento do projeto, optou-se pelo processo modelo estrela, onde a ênfase está na prototipação e testes, integrando o usuário ao processo e validando as soluções apresentadas. Ao fim, tem-se uma interface gráfica com o objetivo de gerar uma experiência de uso boa e eficiente, otimizando o tempo na gestão do estoque, aumentando a produtividade e simplificando tarefas.

Palavras-chave: interface gráfica do usuário, dispositivo de interação móvel, experiência do usuário, usabilidade. 


\section{INTRODUÇÃO}

O presente projeto parte de uma aproximação das acadêmicas com a ContaAzul, startup de gestão financeira online para micro e pequenas empresas, considerada uma das mais inovadoras da América Latina. A parceria visa integrar os conhecimentos da Universidade ao mercado de trabalho, além de ampliar e enriquecer o conhecimento das acadêmicas na área de design para Dispositivos de Interação Móvel (DIM) em crescimento no setor..

Para desenvolvimento do projeto foi utilizado o processo modelo estrela, que aborda a criação de sistemas centrada no usuário como "ondas alternantes", dando ênfase na prototipação rápida e realização de testes com o usuário, onde os resultados são utilizados para a melhoria contínua da interface projetada (ROCHA; BARANAUSKAS, 2003).

Ao fim, obteve-se a Interface Gráfica do Usuário de um aplicativo específico para gerenciamento de estoques, com base na função já existente no site ContaAzul, a fim de tornar o uso mais direto e objetivo. O aplicativo foi desenvolvido com base nos conceitos de UX e testado com usuários, obtendo-se assim a validação dos critérios propostos. A seguir, inicia-se a etapa de fundamentação teórica, onde foram definidos conceitos e critérios de UX para DIM do tipo tablet

\section{A EMPRESA CONTAAZUL}

Nota-se um aumento significativo do número de dispositivos móveis vendidos a cada ano. Segundo o Fórum Brasileiro da Mobile Marketing Association Latam, que aconteceu em setembro de 2014 , os tablets tiveram aumento de $118 \%$ nas vendas no primeiro semestre de 2014 em relação a 2013 (2014, web).

Outro dado importante é da IDC ${ }^{1}$ de 2014 , que relata que o consumo de tablets de janeiro a setembro de 2014 atingiu a marca de 6,4 milhões de unidades (2014, web). A IDC também identificou que, ao final do mês setembro, os tablets correspondiam a $47,7 \%$ do mercado de computadores - acompanhado dos notebooks $(33,1 \%)$ e os computadores de mesa $(19,1 \%)$.

Ainda segundo a IDC, nesse mesmo período, os computadores de mesa registraram vendas 31\% abaixo em comparativo a 2013 e os notebooks sofreram retração de $23 \%$, exemplificando ainda mais a predominância e tendência de crescimento de tablets no mercado brasileiro. Mesmo em comparativo a smartphones, o tablet tem vantagem. A edição de 2015 do relatório Internet Retailer Mobile 500, que analisa os 500 principais varejistas online do mundo, levantou que as vendas mobile acontecem em 59\% das vezes por um tablet, e $41 \%$ de um smartphone (2014, web).

Tais estudos demonstram que cada vez mais as pessoas deverão utilizar seus DIM para acesso a internet. Por isso a importância de disponibilizar serviços e produtos que estejam presentes em todas as plataformas e possuam uma interface prática, de fácil acesso e que permite ao usuário encontrar as informações que procura com rapidez. Essa demanda ainda está em aberto na empresa ContaAzul.

\footnotetext{
${ }^{1}$ International Data Corporation (organizado pela Associação Brasileira de Indústria Elétrica e Eletrônica - Abinee).
} 
Nesse contexto, identificou-se a partir de análise em lojas de aplicativos (Google Play e AppStore) que o atual aplicativo ContaAzul, tem tido pouca aceitação entre os usuários, sendo avaliado em 3,1 onde a nota máxima é 5 . Percebe-se, ao verificar as opiniões dos usuários, que a grande parte do problema tem como foco o Design de Interação e as ferramentas disponibilizadas que não funcionam, além da solicitação de versão do aplicativo para tablet.

A ContaAzul é uma startup brasileira com sede em Joinville/SC que oferece um serviço $100 \%$ online para gestão de micro e pequenas empresas ${ }^{2}$. A empresa surgiu em 2011 quando foi a primeira startup brasileira selecionada pelo programa de aceleração de negócios 500 Startups, no Vale do Silício e lá ficou incubada por quatro meses onde foi possível contato com profissionais e empresas como Facebook, YouTube e Google.

Recebeu a atenção de diversos investidores além de prêmios como "Melhor Web App" do Brazil Startup Award, "Empreendedor de Sucesso da PEGN" na categoria startup, em 2013 e esteve entre as 10 empresas mais inovadoras da América Latina em 2014, pela publicação Fast Company.

Em 2014 a startup cresceu 230\% e prevê mais 100\% para o ano de 2015. Atualmente, a ContaAzul mudou-se do InovaParq, onde possuía uma sede de $400 \mathrm{~m}^{2}$, para o Perini Business Park, ocupando 1,4 $\mathrm{mil} \mathrm{m}^{2}$. Outro reflexo desse crescimento é a previsão de contratação de mais 70 colaboradores até dezembro/2015.

A ContaAzul acredita que o empreendedor deve focar em expandir seus negócios ao invés de perder tempo com burocracias. Para isso, foi criado um sistema de gestão simples, onde em sua versão disponível no aplicativo web, é possível ter uma visão geral da parte financeira da empresa, visualizando o saldo das contas bancárias vinculadas, próximas contas a pagar e receber gráficos de receitas e despesas.

\section{DESENVOLVIMENTO PROJETUAL}

Neste capítulo serão conceituadas e relatadas as técnicas de análise de dados aplicadas no projeto a fim de complementar as informações teóricas expressas no capítulo anterior.

Como Agner (2012) sugere: é necessário unir os desejos da equipe de Design aos dos clientes e usuário. Por isso, em um segundo momento foi consultado o cliente ContaAzul através de entrevista semiestruturada e após, foram levantandos os interesses do usuário através de análise de dados de uso da empresa e consulta de mercado. Essas informações foram representadas por meio de desenvolvimento de personas.

\subsection{Entrevista}

Entrevistas são ferramentas de pesquisa utilizadas para coletar informações e ter contato direto com o participante. As entrevistas podem ser conduzidas remotamente (celular ou mídias sociais) ou pessoalmente (sendo esta última a melhor a maneira, por

\footnotetext{
${ }^{2}$ De acordo com a Lei Geral da Micro e Pequena Empresa (Lei no 123/2006), é considerado Microempreendedor Individual (MEI) quem possui receita bruta anual de até $\mathrm{R} \$ 60$ mil. Microempresas (ME) possuem receita bruta anual de $R \$ 60$ mil até $R \$ 360$ mil e Pequenas Empresas possuem receita bruta anual de $\mathrm{R} \$ 360$ mil até $\mathrm{R} \$$ 3,6 milhões.
} 
possibilitar verificar expressões corporais do entrevistado) (MARTIN; HANINGTON, 2012).

Segundo Preece et al. (2013) as entrevistas podem ser estruturadas, abertas e semiestruturadas (conforme o controle que o entrevistador tem sobre a conversa) ou de grupo (quando envolve um grupo de entrevistados guiado por um facilitador).

O objetivo dessa ferramenta foi conhecer um pouco mais sobre o cliente, suas necessidades e expectativas, etapa essencial para fundamentar as fases de decisões seguintes. O processo iniciou com uma breve visita à estrutura da ContaAzul, conhecendo os espaços, as equipes e dinâmica de trabalho. Inicialmente, já foi possível reconhecer alguns valores da empresa e processos de desenvolvimento de produto (impressões confirmadas após pelo entrevistado).

Em um primeiro momento, o entrevistado comentou rapidamente sobre os 4 anos de empresa, o rápido crescimento (que acarretou na mudança para uma sede maior) e o quadro com 135 funcionários (e mais de 20 vagas em aberto).

Após, foi apresentada a estrutura da equipe de Design que divide-se entre todos os setores da empresa (para cada área existe um designer responsável). A consequência disso é uma equipe com visão universal da ContaAzul e seu produto, garantindo soluções que atendam todas as necessidades.

Atualmente, para medir a satisfação do cliente são usadas algumas métricas de qualidade como a NPS (Net Promoter Score) que avalia a qualidade do serviço através da pergunta "Em uma escala de 0 a 10, o quanto você indicaria o serviço para um amigo?". Além disso, utilizam-se testes A-B (colocar duas versões do produto no ar e mensurar a aceitação de cada uma delas) e testes de usabilidade.

$\mathrm{Na}$ entrevista também foi comentando o padrão visual aplicado a todos os materiais da empresa e outras obrigatoriedades do projeto: Design centrado no usuário, testes de usabilidade e validação das alternativas, aplicação de funções coerentes ao público mobile e uso do manual de marca ContaAzul.

$\mathrm{Na}$ entrevista também foi apresentada a tendência da startup (e também do mercado de aplicativos como um todo) em desmembrar seu site em aplicativos específicos para cada função. Até o momento, a empresa estava desenvolvendo aplicativos para as áreas financeiras e de vendas.

Essa segmentação objetiva o uso do aplicativo, tornando-o mais direto e possibilitando atender à demanda sem agregar funções que o usuário não está buscando durante aquele uso. A fim de escolher a melhor função do site a ser desenvolvida para uso em um DIM foi decidido levar em consideração as duas funções já atendidas (financeiro e vendas), e projetar uma terceira que complemente as anteriores. Sendo assim, os três aplicativos seriam sincronizados entre si (e também com o site).

Com isso, foi escolhido focar no processo de gerenciamento de estoque, essencial para uma boa gestão, informando dados precisos para que o controle e as tomadas de decisão do empresário sejam mais seguras e o controle sobre sua empresa seja completo.

A solicitação de um aplicativo que possibilite o gerenciamento do estoque já foi feita pelos atuais clientes ContaAzul, inclusive através do feedback feito pela Apple Store. O pedido também foi identificado em avaliações de apps de concorrentes, como no Sige Cloud (sistema de gestão também voltado à micro e pequenos empresários). 


\subsection{Protótipos}

O processo de projetar alternativas foi iniciado pelo wireframe a fim de definir as funcionalidades, a estrutura e a interação com o serviço antes de adicionar a superfície do aplicativo (cores, padrões e imagens). Posteriormente, os wireframes foram transformados em protótipos digitais interativos para que fossem testados sem a interferência da estética do aplicativo.

A princípio, foram desenvolvidos manualmente duas opções de wireframe, cada um elaborado por uma das autoras, a partir das funções do site e das adaptações necessárias para dispositivos móveis.

Os dois wireframes foram então comparados e analisados por ambas, a fim de identificar os pontos em comum e também as soluções específicas de cada uma. Com base nisso, foram feitas as adaptações necessárias e elaborado o primeiro wireframe digital.

Para o desenvolvimento do aplicativo, foi levado em consideração o sistema já existente no ContaAzul de segmentação de logins, onde uma empresa pode cadastrar mais de um perfil de acesso, escolhendo quais funções estarão disponíveis para aquele usuário. Assim, administrador e comprador, por exemplo, não têm acesso às mesmas informações. Isso garante que informações sigilosas sejam consultadas apenas por colaboradores autorizados (Figura 1).

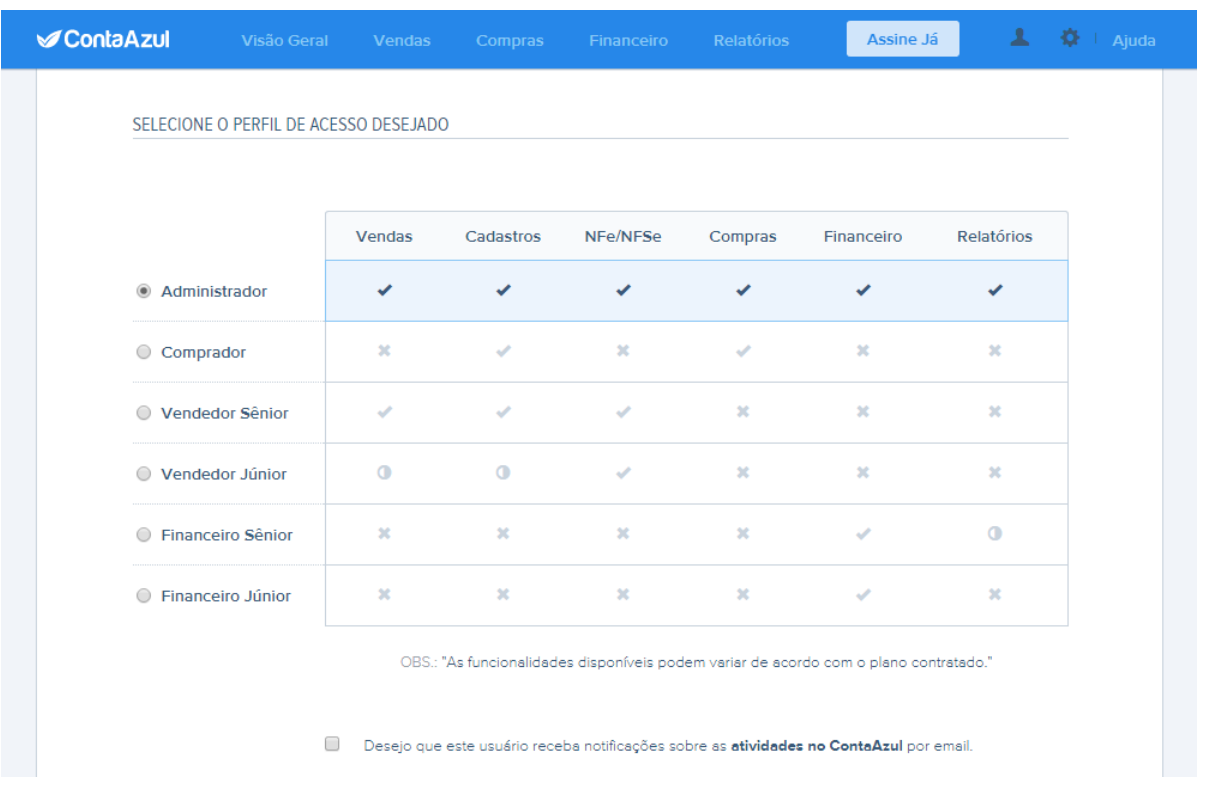

Figura 1 - Cadastro do perfil de acesso

Fonte: Elaborado pelos autores, com base na pesquisa realizada

Para o desenvolvimento do aplicativo, foi levado em consideração o sistema já existente no ContaAzul de segmentação de logins, onde uma empresa pode cadastrar mais de um perfil de acesso, escolhendo quais funções estarão disponíveis para aquele usuário. Assim, administrador e comprador, por exemplo, não têm acesso às mesmas informações. Isso garante que informações sigilosas sejam consultadas apenas por colaboradores autorizados (Figura 1).

As telas desenvolvidas e apresentadas aqui foram planejadas para o acesso do administrador, que visualiza e edita todos os dados do sistema, sendo assim a mais completa. 
Um dos componentes de Experiência do Usuário Móvel é a disponibilidade do sistema, que visa evitar a perda de informações em casos de queda de conexão. Para respeitar esse princípio, o aplicativo funcionará off-line e será sincronizado assim que o usuário tiver acesso à internet.

Inicialmente foi projetada a tela "Meu Estoque" (Figura 2), tela principal que abre após o login, onde o usuário tem acesso a todas as informações mais importantes do seu estoque. Foi aplicada também a mesma linguagem e classificação já existente no site ContaAzul, garantindo a uniformidade não só visual, mas também linguística, para que o usuário não tenha problemas de entendimento e adaptação ao utilizar a versão móvel e a para desktop. Assim, obtém-se uma consistência não só interna (dentro do próprio aplicativo), como também externa (com o site), respeitando um dos princípios de interação.

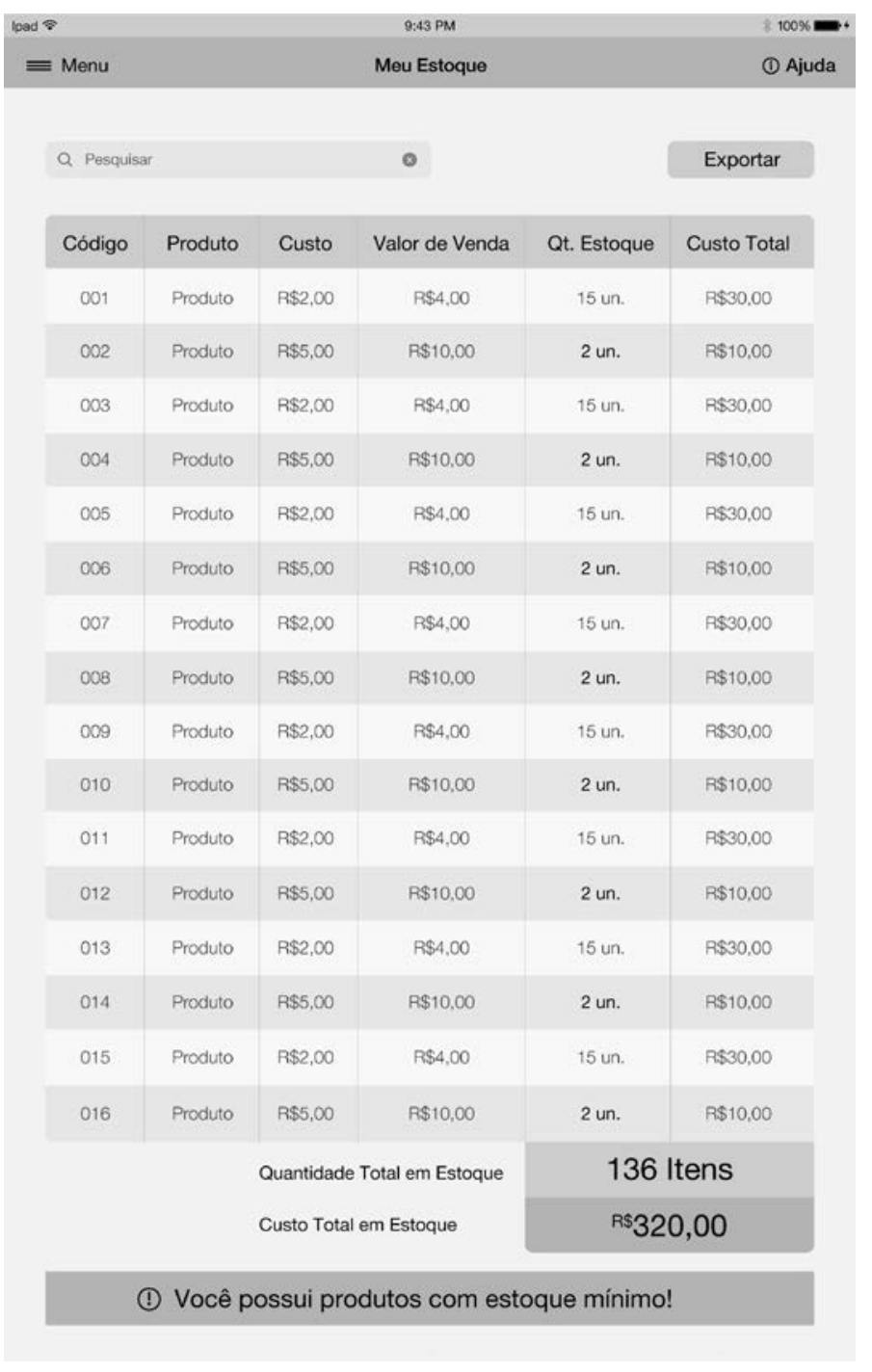

Figura 2 - Tela Meu Estoque

Fonte: Elaborado pelos autores, com base na pesquisa realizada

Inicialmente foi projetada a tela "Meu Estoque" (Figura 2), tela principal que abre após o login, onde o usuário tem acesso a todas as informações mais importantes do seu estoque. Foi aplicada também a mesma linguagem e classificação já existente 
no site ContaAzul, garantindo a uniformidade não só visual, mas também linguística, para que o usuário não tenha problemas de entendimento e adaptação ao utilizar a versão móvel e a para desktop. Assim, obtém-se uma consistência não só interna (dentro do próprio aplicativo), como também externa (com o site), respeitando um dos princípios de interação.

Ao optar pelo menu tipo "hambúrguer" (menu de barra lateral que desliza sobre a tela do aplicativo sinalizado por três linhas horizontais) a fim de otimizar o espaço, foi identificado o principal problema dessa opção: por não estar à vista, muitas vezes o usuário não localiza o menu. Um dos agravantes é o símbolo atualmente utilizado para identificá-lo: três barras horizontais em sequência, uma em cima da outra. Apesar de ser comum e já reconhecível por alguns usuários, ainda não pode ser universalizado, principalmente por não ser uma metáfora clara que tenha semelhança com algo já existente no mundo físico (uma das heurísticas de usabilidade). Para solucionar essa barreira, foi adicionado ao já conhecido ícone a palavra "Menu", uma alternativa simples que garante assim um entendimento mais rápido e claro sobre a função do botão.

Seguindo a mesma lógica de interação, foram criadas as telas principais da interfaces do aplicativo, foram criadas as telas para "Minha Conta" (onde o usuário acessa e pode editar informações básicas como senha e email), a tela de login (composta por uma sequência de ilustrações, a fim de introduzir o usuário ao conteúdo do site) e a tela de carregamento, apresentada enquanto o aplicativo sincroniza as informações com o site e com os outros aplicativos ContaAzul.

Com essas telas desenvolvidas inicialmente foi possível fazer uma prototipação rápida, a fim de iniciar os testes com os primeiros usuários e pontuar as possíveis alterações. Todos os resultados estão registrados no subcapítulo a seguir.

\subsection{Testes com usuários}

Para a primeira rodada de testes foram consultados: um usuário em potencial (aqui intitulado de $A$ ), que atualmente implementa em sua empresa um concorrente ContaAzul para gestão de estoque; um usuário que trabalha com gestão de estoques (aqui intitulado como B), a fim de esclarecer questões sobre a atividade e, por fim, o Anderson Gomes, representante ContaAzul, presente em todas as etapas de teste.

Além disso, o protótipo foi testado pelas autoras com base nas metas de UX e também diretrizes de usabilidade, para garantir que todas as interações e possíveis alterações sejam guiadas pelos requisitos propostos.

Para a prototipação foram utilizados os wireframes, tais como apresentados no subcapítulo anterior, garantindo que, nesse primeiro momento, fossem levados em consideração apenas os aspectos estruturais.

Para todos os testes foi desenvolvido um protótipo digital e interativo, apresentado ao usuário em um iPad (dispositivo para o qual foi projetado).

\subsubsection{Usuário $A$}

O usuário A possui um nível alto de familiaridade com tecnologia e gestão de estoques, o que tornou o teste simples e as críticas apuradas. No dia do teste foi apresentado brevemente o aplicativo e solicitado que realizasse duas tarefas básicas (consultar um determinado produto em estoque + realizar inventário). 
Ambas as funções foram localizadas e executadas com rapidez e sem grandes dificuldades. O pequeno contratempo encontrado foi com a identificação de nomenclaturas, pela não familiaridade com o ContaAzul. Ao terminar as tarefas solicitadas, naturalmente o usuário foi navegando e explorando o aplicativo, enquanto tirava dúvidas e fazia sugestões. Nesse momento, a navegação ficou livre para que fossem observados quais campos chamam mais atenção e quais telas apresentam mais dificuldades. Ao fim, foram registradas as seguintes observações:

- Sugeriu que todas as listagens possuíssem algum tipo de filtro, para que o usuário decida como deseja se organizar;

- Sugeriu que em fornecedor, constasse não apenas o nome da empresa, mas também quem é o seu contato dentro dela;

- Sugeriu incluir a opção de anexar foto ao chamado, pertinente para quando o usuário deseja enviar um screenshot da tela onde está com dúvidas;

- Sugeriu reconsiderar relatório de produtos mais vendidos, pois nem tudo o que sai do estoque é efetivamente vendido (pode gerar confusão no usuário e foge do foco do aplicativo);

Considerou a tela inicial ("Meu Estoque") a mais interessante, por reunir de maneira prática as informações mais pertinentes.

\subsubsection{Usuário $B$}

Ao apresentar o protótipo ao usuário $B$, obteve-se como feedback instruções que, em sua maioria, diziam respeito à rotina de gestão de estoques, já que esta é atualmente a sua função profissional.

Mesmo sem ser cliente ContaAzul, obteve facilidade no uso, identificando rapidamente funções e nomenclaturas, sentindo apenas a falta de uma hierarquização nas listagens (onde fosse possível organizar os itens de outras maneiras, que não apenas a alfabética).

Além dessa observação, elucidou sobre a necessidade de dar um alerta antes do início do inventário, avisando que aqueles itens ficarão bloqueados para a venda até que o inventário seja concluído. Essa medida é necessária para que não haja conflito nos números finais.

Ao fim, o usuário considerou o uso fácil e colocou-se a disposição para testes futuros.

\subsubsection{Feedback ContaAzul}

Por fim, antes de iniciar o desenvolvimento visual, o protótipo foi apresentado ao gerente de design da ContaAzul. Durante o uso (que nesse caso abrangeu o aplicativo todo e não apenas funções específicas), seu maior questionamento foi sobre o cadastro de produtos: será que o usuário móvel conseguiria realizar um cadastro de produto tão completo (com informações fiscais que devem constar na Nota Fiscal) através de um tablet? Para essa pergunta, foram apresentadas duas soluções: eliminar a opção de cadastrar produto ou simplificá-la.

Além dessa observação, foram levantadas as seguintes sugestões:

- Melhorar a hierarquização das informações de produtos e fornecedores;

Ao apresentar a opção de "enviar e-mail", colocar no mesmo padrão das outras ações. 


\subsection{Desenvolvimento visual}

Para o desenvolvimento do layout da interface, foi utilizado como referência o Human Interface Guidelines iOS da Apple, respeitando o manual de identidade ContaAzul disponibilizado pelos mesmos. Devido a questões de sigilo o manual de identidade e desenvovimento de interface não serão apresentados na íntegra.

Por padrão, a tipografia utilizada é a Próxima Nova Regular. Em casos de maior ênfase deve se utilizar a Próxima Nova Semibold e como apoio para títulos ou em casos de tamanho limitado, deve-se utilizar a Próxima Nova Condensed, atentando para o fato de que ela sempre deve ser utilizada em caixa alta. Já a Próxima Nova Light, é utilizada apenas em textos de apoio ou sem muito destaque.

As cores aplicadas na interface dão vida ao aplicativo, ajudam a indicar interatividade e dão consistência visual. A Human Interface Guidelines iOS (2015, web) preza pelo uso de uma paleta de cores que funcione bem individualmente, em combinações, na luz, em fundos claros ou escuros. No caso do presente projeto, foi respeitada a paleta de cores já utilizada pelo ContaAzul, para manter a mesma ênfase e consistência visual entre o site e o aplicativo.

Para padronizar os espaçamentos entre os objetos e hierarquizar os elementos de toda a interface, foi aplicado o mesmo grid já utilizada para a interface web do ContaAzul, que por questões de sigilo, não será apresentada.
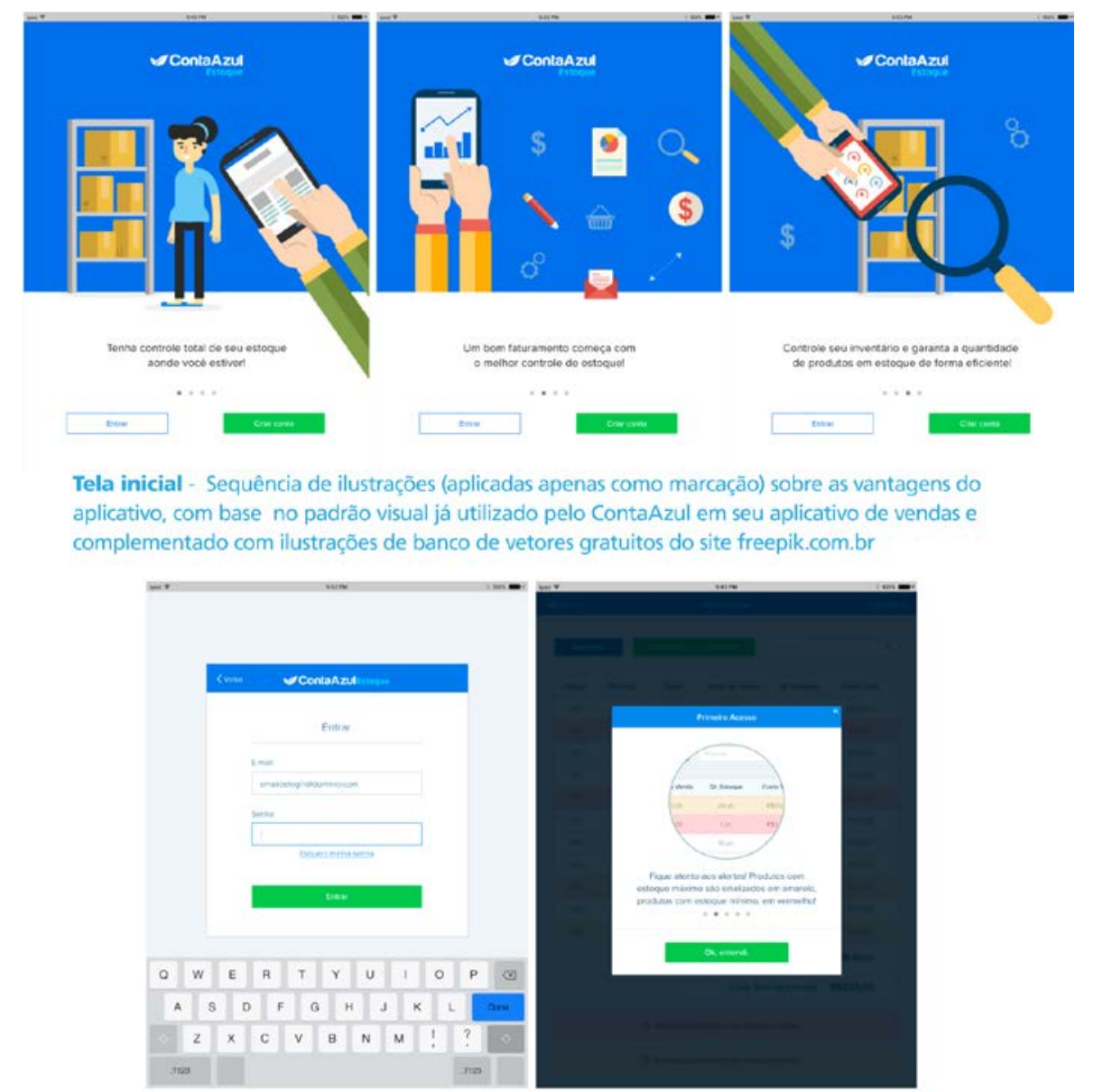

Tela de login e primeiros passos - Ao fazer login aparecem dicas de navegação que guiam o

usuário iniciante às principais funçōes do aplicativo, tais páginas mantiveram-se como no wireframe.

Figura 3 - Tela inicial

Fonte: Elaborado pelos autores, com base na pesquisa realizada 
A utilização do manual de identidade ContaAzul para o desenvolvimento da interface impacta diretamente na eficiência do aplicativo, que proporciona a familiaridade entre as interfaces e consequentemente a boa experiência de uso.

Nesta etapa de desenvolvimento visual, foram também corrigidas falhas identificadas no wireframe e adicionados itens sugeridos pelos usuários. Todas as alterações efetuadas foram guiadas pelas diretrizes de UX, levantadas no capítulo de fundamentação teórica. Conforme as Figuras 3 e 4, seguem as principais telas com o desenvolvimento visual e alterações conforme primeiro teste de usabilidade.
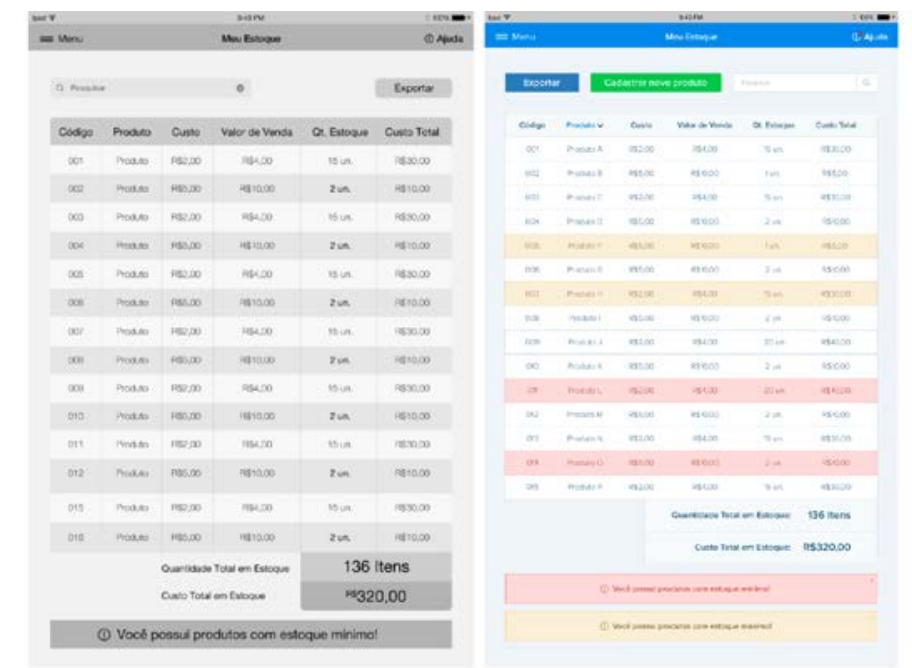

Tela Meu Estoque (antes e depois) - Foi adicionado botão de cadastro de novo produto afim de tornar o acesso mais rápido e a opção de hierarquizar a lista conforme necessidade, sugestão proposta pelos usuários e também encontrada nas diretrizes de usabilidade de Hansen (1971), visando a otimizaçăo da operação. O produto e a mensagem de alerta possuem a mesma cor afim de chamar a atenção do usuário e facilitar sua localizaçăo.
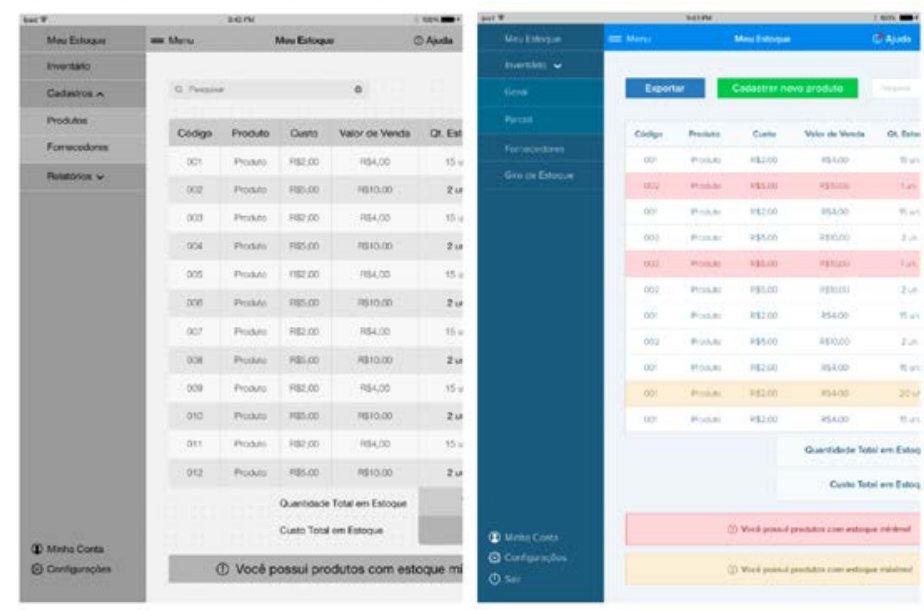

Menu Aberto (antes e depois) - Foi inserido o botão sair, subdividido o item iventário em geral e parcial, visando reduzir o número de telas acessadas até o alcance do objetivo e eliminado o item cadastros (agora presente cada um em sua respectiva tela), mantendo a uniformidade visual e funcional.

Figura 4 - Telas internas

Fonte: Elaborado pelos autores, com base na pesquisa realizada

\subsection{Segunda etapa de testes com usuários}

Após encerrar o desenvolvimento visual, as telas foram novamente transformadas em um protótipo navegável e levadas para teste com usuários. Dessa vez, foram priorizados os micro e pequenos empresários que já utilizam ContaAzul. 
Para a escolha foram contatados através de e-mail quinze clientes previamente selecionados pela ContaAzul. Dos quinze, oito retornaram o e-mail e destes, quatro tinham interesse em participar do teste.

\subsubsection{Usuários A e B}

Os usuários A e $B$, apresentados anteriormente, testaram novamente $\mathrm{O}$ aplicativo após serem efetuadas as alterações e também o desenvolvimento visual. No segundo teste, ambos se mostraram mais à vontade e familiarizados, realizando as tarefas com ainda mais agilidade, apresentando apenas um contratempo durante 0 uso.

Ao início, foi dada a seguinte orientação: utilize o aplicativo considerando que já são clientes e desejam consultar uma quantidade em estoque. Apesar disso, notouse que ambos tentaram por mais de uma vez clicar na opção "criar conta" e foram redirecionados ao site, quando na verdade desejavam efetuar login. Percebeu-se então que a cor verde do botão "criar conta" induzia ao erro, já que o usuário tende a perceber primeiro e mais rápido a cor do que o texto.

Para o usuário $A$, o aplicativo já estava completo e satisfatório, não sugerindo dessa vez nenhuma nova alteração. $O$ usuário $B$ também se demonstrou satisfeito $e$ concluiu o teste sem dificuldades, acrescentando apenas a sugestão de inserir a possibilidade de selecionar apenas alguns itens específicos da listagem de estoque para serem exportados.

\subsubsection{Usuário C}

O usuário $C$ trabalha com monitoramento, rastreamento e gestão de frotas. É cliente ContaAzul e, apesar de já ter utilizado a função de estoque, atualmente não utiliza mais. Ao ser questionado, ele não soube precisar o motivo, mas imagina ser por questões internas. Atualmente, quem cuida do estoque é o diretor da empresa por tratar-se de produtos de alto valor (câmeras e rastreadores).

Ao conhecer o aplicativo, o usuário mostrou-se bastante empolgando, identificando telas que não sabia que eram existentes no site. Ao ser direcionado para as tarefas, não teve dificuldade em nenhuma. O que mais gostou foram as notificações de estoque mínimo e máximo (e da possibilidade de exportá-las para, por exemplo, encaminhar por e-mail).

Sua única dificuldade foi com a transição da tela de primeiros passos onde deveria ser dado um clique para que passassem as telas e o usuário tentou fazer a transição arrastando-as.

Ao fim, notou-se uma boa aceitação por parte do usuário, onde definiu a usabilidade como fácil e intuitiva, principalmente por já seguir a linguagem do site ContaAzul.

\subsubsection{Usuário D}

A empresa onde trabalha o usuário $D$ fornece equipamentos e serviços para a área de T.I. Lá, o usuário cuida do atendimento e também da gestão de estoques. No dia do teste, o usuário relatou que no momento o estoque está desatualizado, porém, fariam um inventário geral no fim de semana seguinte.

Durante o teste as atividades foram realizadas de maneira rápida e sem dificuldades, tendo uma pequena dúvida na tela de transição dos primeiros passos 
(assim como o usuário C). Em sua concepção, as principais facilidades são os alertas de estoque mínimo e máximo e também a praticidade do inventário (pois atualmente o usuário imprime a listagem do site, faz a conferência manualmente e depois digita para o site novamente - o que acarreta em uma perda de tempo desnecessária que poderia ser poupada com o uso do tablet).

Ao fim do teste com o usuário que gerencia o estoque, participou das observações um segundo funcionário da empresa, que também utiliza o sistema ContaAzul. Juntos, concluíram que, se o aplicativo já estivesse disponível, seria um facilitador para a rotina da empresa e também para o inventário geral que iriam realizar em breve.

\subsubsection{Usuário $\mathrm{E}$}

O usuário E é proprietário em uma loja de mobiliário e utiliza o ContaAzul principalmente para gerenciar suas vendas e orçamentos. Atualmente seu estoque não está com as quantidades reais, pois ele tem dificuldade em cadastrar a quantidade que está na loja (pronta entrega) e a quantidade disponível por encomenda.

Durante o teste, o usuário explorou todas as telas e funções, adicionando sempre comentários e feedbacks. Entre eles, sua principal contribuição foi a sugestão de notificação para alertar quando está na hora de fazer inventário novamente, a fim de auxiliar o usuário a manter o seu estoque sempre atualizado garantindo relatórios mais precisos.

\subsubsection{Usuário $F$}

A empresa onde o usuário $F$ trabalha fabrica e comercializa cosméticos em lojas virtuais e físicas em todo o país. Atualmente acessam o ContaAzul com dois perfis diferentes (que diferenciam as informações de acesso) e utilizam para todas as funções da empresa, incluindo gerenciamento de estoque.

O que mais animou o usuário foi a possibilidade de fazer o inventário e registrálo no sistema ao mesmo tempo, sem a necessidade de imprimir a listagem, conferir e depois retornar para o desktop, o que confirma o objetivo do aplicativo de poupar tempo e facilitar a gestão.

Durante o teste e a navegação, o usuário teve apenas dificuldades em identificar os resultados do relatório do "Giro de Estoque", pois na simulação os números não eram fiéis a formula utilizada pelo ContaAzul. No mais, a aceitação e o feedback foram positivos, com uso intuitivo e simples, alcançando o resultado desejado.

A partir dos retornos obtidos e da análise das diretrizes de usabilidade, foram feitas as alterações necessárias, apresentadas na etapa de refinamento descrita no subcapítulo a seguir.

\subsection{Refinamento Visual}

Nessa fase, a solução levada para teste com os usuários foi refinada e as últimas alterações necessárias foram efetuadas. Abaixo, estão apresentadas apenas as telas que foram adicionadas ou passaram por algum tipo de modificação.

$\mathrm{Na}$ tela inicial, o botão entrar mudou de lugar e cor, a fim de evitar que o usuário confunda-se na hora do login (como ocorrido durante os os testes). Já na tela "Meu 
Estoque" foi adicionada a opção de selecionar os itens que deseja exportar, permitindo assim a personalização da lista exportada conforme necessidade (sugestão esta apresentada por um dos usuários).

Na tela "Minha Conta), o usuário pode visualizar e atualizar seus dados, como email e senha de acesso. Na tela "Configurações", é possível escolher e cadastrar um novo perfil de acesso, além de agendar o alerta para realização do inventário colaborando assim para que este seja realizado dentro das necessidades da empresa, mantendo-o sempre atualizado, garantindo que os relatórios sejam fieis a realidade da empresa, tornando o controle mais eficiente.

Para dar apoio às interrupções, conforme aconselhado nos princípios de interação móvel apresentados na fundamentação teórica, foi elaborado uma tela de alerta para quando o aplicativo é encerrado inesperadamente (como no descarregamento da bateria, por exemplo). Nele, o usuário tem a possibilidade de retomar os dados que foram cadastrados e não foram salvos, garantindo que nenhuma informação seja perdida. Em seguida, foi desenvolvida a simulação do alerta para efetuar o inventário. Nele, é possível adiar o lembrete ou realizá-lo imediatamente o inventário.

Assim, conclui-se a etapa de refinamento visual com todas as alterações efetuadas, alcançando os objetivos propostos e visando sempre atender as necessidades dos usuários e também as diretrizes de UX.

\section{REFERÊNCIAS}

AGNER, Luiz. Ergodesign e arquitetura de informação: trabalhando com o usuário. 3. ed. Rio de Janeiro: Quartet, 2012.

ROCHA, Heloísa Vieira da. BARANAUSKAS, Maria Cecília Calani. Design e Avaliação de Interfaces Humano-Computador. Campinas, SP: NIED/UNICAMP, 2003.

SEBRAE. Anuário do trabalho na Micro e Pequena Empresa. Serviço Brasileiro de Apoio as Micro e Pequenas Empresas. Departamento Intersindical de Estatística e Estudos Socioeconômico. Brasília, DF: DIEESE, 2011. Disponível em: <http://www.dieese.org.br/anuario/2011/anuarioSebrae10-11.pdf>. Acesso em: 20. jun. 2015.

SEBRAE. Especialistas em pequenos negócios. S.D. Disponível em: <www.sebrae.com.br/Sebrae/Portal\%2520Sebrae/Anexos/Novo\%2520MPE\%2520Indi cadores\%2520-\%252023\%252007\%25202014. pdf+\&cd=2\&hl=pt-BR\&ct=clnk\&gl=br>. Acesso em: 20. jun. 2015.

SEBRAE. MPE INDICADORES Pequenos negócios no Brasil. Universidade Corporativa Sebrae. Disponível em: <http://goo.gl/OUhULE >. Acesso em 20. jul. 2015.

WROBLEWSKI, Luke. Touch Gesture Reference Guide. 2010. Disponível em:<http://www.lukew.com/ff/entry.asp?1071>. Acesso em: 14 jul. 2015. 